\title{
High prevalence of COPD in atherosclerosis patients
}

\author{
This article was published in the following Dove Press journal: \\ International Journal of COPD \\ 19 October 2017 \\ Number of times this article has been viewed
}

\author{
Izabela Tuleta \\ Tarik Farrag \\ Laura Busse \\ Carmen Pizarro \\ Christian Schaefer \\ Simon Pingel \\ Georg Nickenig \\ Dirk Skowasch \\ Nadjib Schahab \\ Department of Internal Medicine \\ II - Cardiology, Pulmonology and \\ Angiology, University of Bonn, \\ Bonn, Germany
}

Correspondence: Izabela Tuleta Department of Internal Medicine II - Cardiology, Pulmonology and Angiology, University of Bonn, SigmundFreud-Str 25, 53105 Bonn, Germany Tel +49228 287I 6670

Fax +49 228 287I 6423

Email izat@gmx.de

\begin{abstract}
Atherosclerosis and COPD are both systemic inflammatory diseases that may influence each other. The aim of the present study was to determine the prevalence of COPD in patients with cerebral and/or peripheral artery disease and to assess factors associated with the presence of COPD. Following the diagnosis of cerebral and/or peripheral artery disease by means of duplex sonography, 166 consecutive patients underwent body plethysmography with capillary blood gas analysis. Thereafter, blood tests with determination of different parameters such as lipid profile, inflammatory and coagulation markers were conducted in remaining 136 patients who fulfilled inclusion criteria of the study. Thirty-six out of 136 patients suffered from COPD, mostly in early stages of the disease. Residual volume indicating emphysema was increased $(162.9 \% \pm 55.9 \%$ vs $124.5 \% \pm 37.0 \%, p<0.05)$ and diffusion capacity was decreased $(55.1 \% \pm 19.5 \%$ vs $75.3 \% \pm 18.6 \%, p<0.05$ ) in COPD patients vs non-COPD group. In capillary blood gas analysis, COPD patients had lower partial pressure of oxygen $(70.9 \pm 11.5 \mathrm{vs} 75.2 \pm 11.0 \mathrm{mmHg}, p<0.05)$ and higher partial pressure of carbon dioxide $(36.8 \pm 7.5$ vs $34.4 \pm 4.4 \mathrm{mmHg}, p<0.05)$ compared with non-COPD individuals. Presence of COPD was associated with predominance of diabetes mellitus, interleukin-8-related systemic neutrophilic inflammation and anemia. In conclusion, COPD is highly prevalent in patients with atherosclerotic artery disease.
\end{abstract}

Keywords: cerebral artery disease, peripheral artery disease, lung function, capillary blood gas, diabetes mellitus, inflammation, interleukin-8, anemia

\section{Introduction}

Atherosclerosis and COPD are very common disorders that are the leading causes of the morbidity and mortality. ${ }^{1,2}$ Atherosclerosis and COPD are both systemic inflammatory diseases that share common risk factors/pathways and thereby may occur more frequently in the presence of each other. ${ }^{3,4}$ There are many studies that identified COPD as an independent predictor of atherosclerosis. ${ }^{5,6}$ Conversely, little is known about the potential impact of atherosclerosis on COPD development and progression. Therefore, the aim of our present study was to assess the prevalence of COPD in patients with atherosclerotic artery disease. Additional goal was to determine factors that are associated with the presence of COPD.

\section{Materials and methods}

\section{Study population}

The present study was conducted between May 2016 and February 2017. The inclusion criterion was confirmation of atherosclerotic cerebral and/or peripheral artery disease in duplex sonography and ability of a patient to conduct properly breathing maneuvers during body plethysmography. Exclusion criterion was identification of restrictive pattern defined as total lung capacity (TLC) $<80 \%$ of a predicted value. 
One hundred sixty-six patients with atherosclerotic artery disease underwent lung function test by body plethysmography. Thirty patients either showing restrictive ventilatory patterns or being unable to perform adequately lung function test were excluded from the study. Remaining 136 patients were included in the study. One hundred twenty-seven of these patients were out-patients who visited our angiological department either for control examination of the already known atherosclerotic artery disease or for the first time with suspected atherosclerotic artery disease to obtain appropriate diagnosis and therapy. Nine patients were stationary patients who were subjected to the interventional angiological treatment. All 136 patients were divided into 2 groups according to the presence of COPD. COPD was defined as a post-bronchodilator airflow limitation of forced expiratory volume in $1 \mathrm{~s}\left(\mathrm{FEV}_{1}\right)$ to forced vital capacity (FVC) of $<70 \%$. According to the Global initiative for chronic obstructive lung disease (GOLD), COPD severity was divided into 4 grades based on $\mathrm{FEV}_{1} \%$ predicted: stage I: FEV $_{1} \geq 80 \%$, stage II: $80 \%>\mathrm{FEV}_{1} \geq 50 \%$, stage III: $50 \%>$ $\mathrm{FEV}_{1} \geq 30 \%$ and stage IV: $\mathrm{FEV}_{1}<30 \%{ }^{{ }^{7-9}}$

A questionnaire was used to collect baseline characteristics of patients such as body weight and height for the subsequent calculation of the body mass index (BMI) and the presence of coronary heart disease, cardiovascular risk factors: arterial hypertension, diabetes mellitus, hypercholesterolemia and nicotine abuse, as well as autoimmune diseases, COPD, asthma, allergies, inhalation therapy in bronchial disorders and oral cortisone treatment.

The research was conducted according to the principles of the Declaration of Helsinki and was approved by the ethics committee of the University of Bonn (ethics approval number: 388/15). Written informed consent was obtained from all subjects.

\section{Angiological examinations}

Angiological diagnostics comprised Doppler sonography, color-coded duplex sonography (ie, 33 Philips, Philips, Amsterdam, the Netherlands) and the measurement of ankle brachial index (ABI). Presence of atherosclerotic artery disease was defined by $\geq 1$ atherosclerotic plaque in duplex sonography. ABI was calculated as the ratio of the blood pressure at the ankle to the blood pressure in the upper arm. An ABI $>1.3$ was associated with increased vascular stiffness and the presence of media sclerosis. ${ }^{10}$ Relevant cerebral artery stenosis was defined as at least 50\% narrowing of the lumen of the brain-supplying artery. Patients with peripheral artery disease underwent Fontaine classification (Table 1). ${ }^{11}$
Table I Fontaine classification

\begin{tabular}{ll}
\hline Stage & Symptoms \\
\hline I & Asymptomatic, incomplete blood vessel obstruction \\
II & Mild claudication pain in limb \\
IIA & Claudication at a distance $>200 \mathrm{~m}$ \\
IIB & Claudication at a distance $<200 \mathrm{~m}$ \\
III & Rest pain, mostly in the feet \\
IV & Necrosis and/or gangrene of the limb \\
\hline
\end{tabular}

Note: Data from a previous study."

\section{Body plethysmography and capillary blood gas analysis}

$\mathrm{FEV}_{1}, \mathrm{FEV}_{1} / \mathrm{FVC}$, residual volume (RV), dynamic total pulmonary resistance (Rtot), TLC and diffusion capacity of lung for carbon monoxide (DLCO) in a single breath method were assessed by body plethysmography (Bodyplethismograph, Aveo-Diffusiontest, Jaeger GmbH, Wuerzburg, Germany). Predicted values for the above parameters were calculated automatically based on age, sex, height and race by the software of the pulmonary function test, according to the pulmonary function reference equations. ${ }^{12}$ Percentages of the predicted values for FEV 1 , RV, Rtot, TLC and DLCO and absolute value for $\mathrm{FEV}_{1} / \mathrm{FVC}$ were used for the subsequent statistical analysis. In the arterialized capillary blood gas analysis, partial pressure of oxygen $\left(\mathrm{pO}_{2}\right)$ and partial pressure of carbon dioxide $\left(\mathrm{pCO}_{2}\right)$ were determined. Five to ten minutes after the application of the vasodilating cream (Finalgon composed of Nonivamid + Nicoboxil, Boehringer Ingelheim Pharma GmbH \& Co.KG, Ingelheim am Rhein, Germany) to the lower tip of the right earlobe, the blood sampling was performed by the use of an automated incision device and a capillary tube. The collected blood was immediately analyzed in a blood gas analyzer.

\section{Blood tests}

The following blood parameters were determined at the time point of the body plethysmography conduction: sodium, potassium, creatinine, glomerular filtration rate (GFR), lipoprotein (a), interleukin-6, interleukin-8, high-sensitivity C-reactive protein (CRP), fibrinogen and complete blood count. Anemia was defined as hemoglobin $(\mathrm{Hb})$ level of $<13 \mathrm{~g} / \mathrm{dL}(8.1 \mathrm{mmol} / \mathrm{L})$ in men and $12 \mathrm{~g} / \mathrm{dL}(7.5 \mathrm{mmol} / \mathrm{L})$ in women, based on the World Health Organization guidelines. ${ }^{13}$ GFR was calculated according to the Chronic Kidney Disease Epidemiology Collaboration (CKD-EPI) equation. The CKD-EPI equation is more accurate in estimating GFR and prognosis, especially at higher GFR levels than the 2006 Modification of Diet in Renal Disease Study equation. ${ }^{14,15}$ 


\section{Statistical analysis}

Statistical analysis was conducted with SPSS Statistics, version 23 (IBM Corp., Armonk, NY, USA). Parametric values were expressed as means \pm SD. Differences between the means of 2 groups were assessed by the Student's $t$-test. Comparisons between categorical variables were performed by use of the chisquare test. $p<0.05$ was considered as statistically significant.

\section{Results}

\section{Prevalence of COPD and characteristics of study patients}

Thirty-six of 136 patients suffered from COPD (Table 2). Most of them $(n=22)$ were in GOLD grade II (Figure 1), followed by patients in GOLD grade I $(n=8)$. Only a few patients were in GOLD grades III $(n=3)$ and IV $(n=3)$. COPD patients were characterized by the relevantly decreased

Table 2 Baseline characteristics of COPD and non-COPD patients

\begin{tabular}{|c|c|c|c|}
\hline & $\begin{array}{l}\text { COPD } \\
n=36\end{array}$ & $\begin{array}{l}\text { Non-COPD } \\
n=100\end{array}$ & $p$-values \\
\hline Age (years), mean $\pm S D$ & $72.4 \pm 8.6$ & $68.9 \pm 12.0$ & 0.114 \\
\hline Male sex, n (\%) & $20(55.6)$ & 7I (7I.0) & 0.091 \\
\hline BMI $\left(\mathrm{kg} / \mathrm{m}^{2}\right)$, mean $\pm \mathrm{SD}$ & $27.3 \pm 5.2$ & $27.3 \pm 4.5$ & 0.978 \\
\hline AOD, n (\%) & $36(100.0)$ & $100(100.0)$ & \\
\hline CAD, n (\%) & $26(72.2)$ & $73(73.0)$ & 0.430 \\
\hline with $<50 \%$ stenosis, $\mathrm{n}(\%)$ & $22(6 I . I)$ & $68(68.0)$ & \\
\hline with $\geq 50 \%$ stenosis, $\mathrm{n}(\%)$ & $4(11.1)$ & $5(5.0)$ & \\
\hline PAD, n (\%) & $34(94.4)$ & $91(91.0)$ & 0.516 \\
\hline Fontaine I, n (\%) & $20(55.6)$ & $70(70.0)$ & \\
\hline Fontaine $2 \mathrm{a}, \mathrm{n}(\%)$ & $6(16.7)$ & $7(7.0)$ & \\
\hline Fontaine $2 \mathrm{~b}, \mathrm{n}(\%)$ & $6(16.7)$ & $13(13.0)$ & \\
\hline Fontaine 3, n (\%) & I (2.8) & $0(0.0)$ & \\
\hline Fontaine $4, \mathrm{n}(\%)$ & $\mathrm{I}(2.8)$ & $\mathrm{I}(\mathrm{I} .0)$ & \\
\hline Media sclerosis, n (\%) & $5(13.9)$ & $19(19.0)$ & 0.490 \\
\hline CHD, n (\%) & $13(36.1)$ & $35(35.0)$ & 0.905 \\
\hline Arterial hypertension, $\mathrm{n}(\%)$ & $29(80.6)$ & $86(86.0)$ & 0.438 \\
\hline Diabetes mellitus, n (\%) & $12(33.3)$ & $17(17.0)$ & 0.040 \\
\hline Hypercholesterolemia, n (\%) & $27(75.0)$ & $69(69.0)$ & 0.498 \\
\hline Nicotine abuse & & & 0.218 \\
\hline never smoker, n (\%) & $10(27.8)$ & $35(35.0)$ & \\
\hline current smoker, n (\%) & $3(8.3)$ & $17(17.0)$ & \\
\hline former smoker, n (\%) & $23(63.9)$ & $48(48.0)$ & \\
\hline pack-years, mean $\pm S D$ & $37.0 \pm 45.1$ & $18.4 \pm 26.8$ & 0.004 \\
\hline Autoimmune diseases, n (\%) & $9(25.0)$ & $23(23.0)$ & 0.808 \\
\hline Self-referred COPD, n (\%) & $13(36.1)$ & $4(4.0)$ & $<0.001$ \\
\hline Self-referred asthma, n (\%) & $\mathrm{I}(2.8)$ & $4(4.0)$ & 0.738 \\
\hline Allergy, n (\%) & $8(22.2)$ & $23(23.0)$ & 0.924 \\
\hline $\begin{array}{l}\text { Inhalation therapy of } \\
\text { bronchial disorders, } \mathrm{n}(\%)\end{array}$ & 14 (38.9) & $9(9.0)$ & $<0.001$ \\
\hline Oral cortisone, n (\%) & $5(13.9)$ & $6(6.0)$ & 0.137 \\
\hline
\end{tabular}

Notes: Data are presented as a mean \pm SD or $\mathrm{n}(\%) . p<0.05=$ significant. Abbreviations: AOD, arterial occlusive disease; BMI, body mass index; $C A D$, cerebral artery disease; CHD, coronary heart disease; PAD, peripheral artery disease.

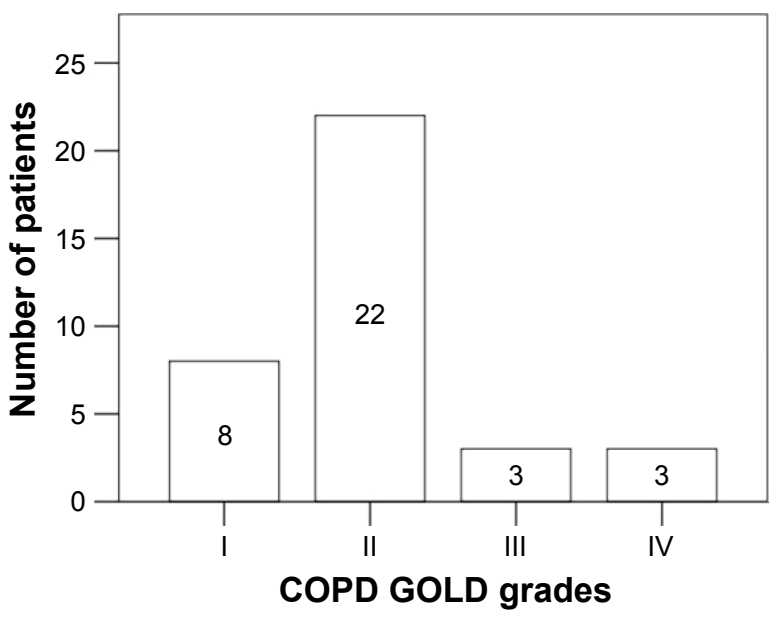

Figure I Predominance of COPD in early stages of the disease. Note: Data are presented as n.

Abbreviation: GOLD, global initiative for chronic obstructive lung disease.

airflow obstruction-related parameters measured by body plethysmography compared with the non-COPD group: FEV ${ }_{1} \%$ predicted: $66.4 \% \pm 20.3 \%$ vs $97.5 \% \pm 19.6 \%$, $\mathrm{FEV}_{1} / \mathrm{VC}: 57.2 . \% \pm 12.6 \%$ vs $82.3 \% \pm 7.9 \%, \mathrm{RV} \%$ predicted: $162.9 \% \pm 55.9 \%$ vs $124.5 \% \pm 37.0 \%$, Rtot $\%$ predicted: $149.9 \% \pm 87.8 \%$ vs $79.6 \% \pm 28.0 \%$, TLC $\%$ predicted: $110.7 \% \pm 20.6 \%$ vs $102.0 \% \pm 17.1 \%$ and DLCO $\%$ predicted: $55.1 \% \pm 19.5 \%$ vs $75.3 \% \pm 18.6 \%, p<0.05$ for each (Figure 2 ). In the capillary blood gas analysis of COPD patients, $\mathrm{pO}_{2}$ and $\mathrm{pCO}_{2}$ were, respectively, significantly lower and higher in comparison with the non-COPD group: $70.9 \pm 11.5$ vs $75.2 \pm 11.0 \mathrm{mmHg}$ and $36.8 \pm 7.5 \mathrm{vs} 34.4 \pm 4.4 \mathrm{mmHg}, p<0.05$ for each (Figure 3 ). There were no significant differences in age, sex and BMI between COPD and non-COPD group (Table 2). Based on the inclusion criterion, atherosclerotic artery disease was present in all patients from both groups. Peripheral artery disease was predominant and detected

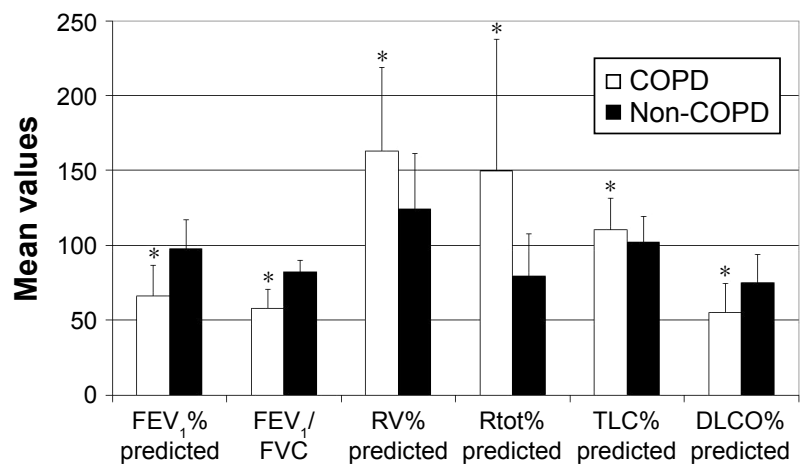

Figure 2 Body plethysmography parameters in COPD and non-COPD patients. Notes: Data are presented as a mean \pm SD. ${ }^{*} p<0.05$.

Abbreviations: DLCO, diffusion capacity of lung for carbon monoxide; $\mathrm{FEV}_{1}$, forced expiratory volume in I second; FVC, forced vital capacity; RV, residual volume; Rtot. dynamic total pulmonary resistance; TLC, total lung capacity. 


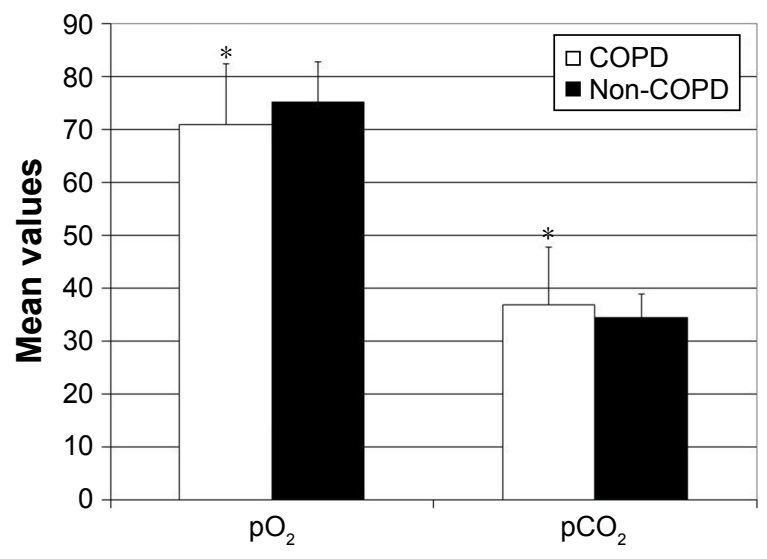

Figure 3 Capillary blood gas analysis in COPD and non-COPD patients. Notes: Data are presented as a mean \pm SD. ${ }^{*} p<0.05$.

Abbreviations: $\mathrm{pO}_{2}$, partial pressure of oxygen; $\mathrm{pCO}_{2}$, partial pressure of carbon dioxide.

in $>90 \%$ of patients in each group. Cerebral artery disease was demonstrated in more than $70 \%$ of patients in respective collectives. The prevalence of coronary heart disease amounted to approximately one-third of patients in each group. The distribution of cardiovascular risk factors such as arterial hypertension and hypercholesterolemia was similar across the groups. Diabetes mellitus was significantly more frequent in the COPD group. Although there were no relevant differences in the smoking habitus between both populations, the amount of smoked cigarettes expressed as pack-years was higher in COPD patients. In 13 out of 36 COPD patients, the diagnosis of COPD had already been known and COPD was treated with inhaled anti-obstructive drugs. One patient in the COPD group reported to have asthma, but according to the guidelines mentioned previously defining COPD as, opposed to asthma, persistent airflow limitation of $\mathrm{FEV}_{1} / \mathrm{VC}<70 \%$ following use of bronchodilatator, this diagnosis was not correct. Inversely, 4 individuals from the non-COPD group indicated to suffer from COPD, which could not be confirmed in the present tests. Generally, significantly more patients were under inhaled anti-obstructive therapy in COPD vs non-COPD group. There were no significant differences in the prevalence of allergies, autoimmune diseases or oral cortisone treatment between both groups.

\section{Predominance of neutrophilic inflammation and anemia in COPD patients}

The analysis of the blood test results revealed that the patients from COPD and non-COPD groups suffered from renal insufficiency (Table 3). High-sensitivity CRP, interleukin-6 and fibrinogen did not differ between COPD and non-COPD
Table 3 Blood test results in COPD and non-COPD patients

\begin{tabular}{|c|c|c|c|}
\hline & $\begin{array}{l}\text { COPD } \\
n=36\end{array}$ & $\begin{array}{l}\text { Non-COPD } \\
n=100\end{array}$ & p-values \\
\hline Creatinine $(\mu \mathrm{mol} / \mathrm{L})$ & $97.4 \pm 35.4$ & $106.2 \pm 88.5$ & 0.497 \\
\hline $\operatorname{GFR}\left(\mathrm{mL} / \mathrm{min} / \mathrm{l} .73 \mathrm{~m}^{2}\right)$ & $58.2 \pm 14.7$ & $60.5 \pm 13.0$ & 0.436 \\
\hline Lipoprotein (a) (nmol/L) & $88.6 \pm 99.4$ & $68.3 \pm 70.8$ & 0.298 \\
\hline Interleukin-6 (pg/mL) & $4.2 \pm 2.1$ & $4.9 \pm 6.4$ & 0.594 \\
\hline Interleukin-8 (pg/mL) & $13.5 \pm 13.3$ & $9.2 \pm 4.9$ & 0.030 \\
\hline hsCRP (nmol/L) & $13.3 \pm 8.6$ & $10.5 \pm 6.7$ & 0.141 \\
\hline Fibrinogen $(\mu \mathrm{mol} / \mathrm{L})$ & $10.9 \pm 2.4$ & $10.6 \pm 5.6$ & $0.84 I$ \\
\hline Leukocytes (G/L) & $8.3 \pm 4.6$ & $7.6 \pm 2.1$ & 0.256 \\
\hline Neutrophils (\%) & $67.9 \pm 8.7$ & $61.4 \pm 10.7$ & 0.012 \\
\hline Lymphocytes (\%) & $19.8 \pm 8.7$ & $26.5 \pm 9.2$ & 0.003 \\
\hline Monocytes (\%) & $9.2 \pm 2.0$ & $8.6 \pm 2.5$ & 0.275 \\
\hline Eosinophils (\%) & $2.4 \pm 1.5$ & $2.7 \pm 3.2$ & 0.697 \\
\hline Basophils (\%) & $0.6 \pm 0.3$ & $0.7 \pm 0.3$ & 0.463 \\
\hline Erythrocytes (T/L) & $4.3 \pm 0.7$ & $4.5 \pm 0.6$ & 0.049 \\
\hline Hemoglobin $(\mathrm{mmol} / \mathrm{L})$ & $7.7 \pm 1.2$ & $8.5 \pm 1.1$ & 0.001 \\
\hline Hematocrit (\%) & $37.7 \pm 5.3$ & $40.2 \pm 4.9$ & 0.015 \\
\hline $\mathrm{MCV}(\mathrm{fL})$ & $88.6 \pm 5.9$ & $89.0 \pm 4.4$ & 0.691 \\
\hline $\mathrm{MCH}$ (fmol) & $1.8 \pm 0.1$ & $1.9 \pm 0.1$ & 0.003 \\
\hline $\mathrm{MCHC}(\mathrm{mmol} / \mathrm{L})$ & $20.4 \pm 0.8$ & $21.0 \pm 1.4$ & 0.011 \\
\hline RDW (\%) & $14.7 \pm 3.7$ & $13.3 \pm 1.2$ & 0.002 \\
\hline Thrombocytes (G/L) & $234.3 \pm|4| .4$ & $230.6 \pm 62.5$ & 0.838 \\
\hline
\end{tabular}

Notes: Data are presented as a mean \pm SD. $p<0.05=$ significant.

Abbreviations: GFR, glomerular filtration rate; hsCRP, high-sensitivity C-reactive protein; MCV, mean corpuscular volume; $\mathrm{MCH}$, mean corpuscular hemoglobin; $\mathrm{MCHC}$, mean corpuscular hemoglobin concentration; RDW, red blood cell distribution width

patient collectives. Lipoprotein (a) measurements showed a tendency toward higher values in the COPD group; however, because of the high standard deviation, without statistical significance. Concentration of interleukin- 8 was relevantly increased in the COPD $(13.5 \pm 13.3 \mathrm{pg} / \mathrm{mL})$ vs non-COPD group $(9.2 \pm 4.9 \mathrm{pg} / \mathrm{mL})$. Leukocyte number tended to be higher in the COPD population $(8.3 \pm 4.6 \mathrm{G} / \mathrm{L}$ vs 7.6 $\pm 2.1 \mathrm{G} / \mathrm{L})$. An analysis of leukocyte subsets demonstrated elevated percentage of neutrophils $(67.9 \% \pm 8.7 \%)$ and decreased percentage of lymphocytes $(19.8 \% \pm 8.7 \%)$ in COPD compared with non-COPD group $(61.4 \% \pm 10.7 \%$, $26.5 \% \pm 9.2 \%$, resp, $p<0.05$ for each). Examination of red blood cell indices showed that the following parameters were significantly reduced in COPD compared with non-COPD patients: erythrocyte number $(4.3 \pm 0.7 \mathrm{~T} / \mathrm{L}$ vs $4.5 \pm 0.6 \mathrm{~T} / \mathrm{L}), \mathrm{Hb}(7.7 \pm 1.2 \mathrm{mmol} / \mathrm{L}$ vs $8.5 \pm 1.1 \mathrm{mmol} / \mathrm{L}$, specifically for women: $7.4 \pm 1.2 \mathrm{mmol} / \mathrm{L}$ vs $8.1 \pm 0.8 \mathrm{mmol} / \mathrm{L}$, for men: $7.9 \pm 1.2 \mathrm{mmol} / \mathrm{L}$ vs $8.6 \pm 1.2 \mathrm{mmol} / \mathrm{L})$, hematocrit $(37.7 \% \pm 5.3 \%$ vs $40.2 \% \pm 4.9 \%)$, mean corpuscular $\mathrm{Hb}$ (MCH: $1.8 \pm 0.1 \mathrm{fmol}$ vs $1.9 \pm 0.1 \mathrm{fmol})$ and mean corpuscular $\mathrm{Hb}$ concentration (MCHC: $20.4 \pm 0.8 \mathrm{mmol} / \mathrm{L}$ vs $21.0 \pm 1.4 \mathrm{mmol} / \mathrm{L}$ ). Erythrocyte distribution width was relevantly increased in 
COPD group vs non-COPD group (red blood cell distribution width [RDW]: $14.7 \% \pm 3.7 \%$ vs $13.3 \% \pm 1.2 \%$ ).

\section{Discussion}

Our present study shows a high prevalence of COPD among patients with atherosclerosis. In a general German population, the prevalence of COPD was estimated to be $\sim 13 \%$ depending on age and smoking habits. ${ }^{16}$ Similar result was obtained in the collective of Japanese patients consulting clinics for nonrespiratory diseases. However, reversibility testing was not performed in this study, so that other respiratory disorders such as asthma may have partly accounted for the diagnosed airflow limitation. ${ }^{17}$ In other Japanese study, airflow limitation as a result of different conditions such as newly and previously diagnosed COPD, asthma, heart failure, etc., was demonstrated in $26 \%$ of patients who underwent spirometry as a preoperative evaluation for elective surgeries. ${ }^{18}$ In Middle Eastern patients with acute coronary syndrome, the prevalence of COPD was $5.3 \%$ and was associated with higher risk of heart failure. ${ }^{19}$ In patients with lifestyle-related diseases, COPD detection frequency amounted to $22.5 \%$; herein, the prevalence of COPD was the highest in individuals with atherosclerosis (about 29\%). ${ }^{20}$ This last result showed even higher detection of COPD in atherosclerosis patients than in our present work (26\%); however, in the study of Matsumoto et al, the data collection was carried out retrospectively using electronic medical records. ${ }^{20}$ In comparison with some other reports, our study was a prospective one, with the use of reversibility test, when appropriate, to rule out conditions other than COPD underlying obstructive respiratory disorders and based not only on spirometry but also on the body plethysmography with measurements of diffusion capacity and blood gas analysis. Therefore, we could exclude a concomitant restriction and better quantify the degree of obstructive disorders with their impact on the blood gas parameters. ${ }^{21}$ Indeed, patients with COPD had, besides reduced $\mathrm{FEV}_{1} / \mathrm{VC}$ and $\mathrm{FEV}_{1}$ \% values, elevated $\mathrm{RV} \%$ measures implying relevant emphysema. Decreased DLCO \% could partly explain reduced $\mathrm{pO}_{2}$ and increased $\mathrm{pCO}_{2}$ values compared with non-COPD study participants.

Pathomechanisms explaining the identification of a high proportion of patients suffering from atherosclerosis to have concurrently COPD are not clear. In our work, diabetes mellitus was significantly more frequent in patients with COPD than in non-COPD patients. It has been shown that diabetes mellitus occurs more often in COPD individuals. Similar pathological processes such as inflammation, oxidative stress, hyperglycemia, reduced physical activity and nicotine abuse may constitute a link between these 2 conditions. In addition, therapy with corticosteroids may increase the risk of glucose intolerance. ${ }^{22}$ Furthermore, we have demonstrated that COPD patients had higher neutrophil percentages in blood compared with the non-COPD group. Smoke-induced neutrophilic inflammation was presented in a mouse model of COPD. ${ }^{23}$ In the recent clinical trial, COPD patients exhibited a prominent airway and systemic inflammation compared with healthy subjects. ${ }^{24}$ Along with the predominance of systemic neutrophilia in our work, increased blood levels of interleukin-8 were detected in COPD population. Elevated blood concentrations of certain cytokines, mainly interleukin (IL)-8 reinforce and maintain inflammation in COPD, even after smoking cessation. ${ }^{25}$ Stimulated human airway smooth muscle cells release IL-8. ${ }^{26}$ IL-8 is known to induce neutrophilia. ${ }^{26}$ In other studies, further markers of systemic inflammation such as high-sensitivity C-reactive protein (hsCRP), fibrinogen, IL-6 and TNF- $\alpha$ were elevated in COPD patients. ${ }^{27,28}$ In our present work, no relevant differences were found in the blood levels of hsCRP, fibrinogen or IL-6 between COPD and non-COPD groups. It could be caused by the relatively low number of enrolled study participants, heterogeneity of population and the presence of pronounced atherosclerosis not only in COPD, but also in the non-COPD (= control) group, which itself is a chronic inflammatory disease. Another finding of our work was the identification of anemic patients in COPD group vs nonCOPD individuals. Anemia is an important comorbidity of COPD and is related to more frequent COPD exacerbations, increased mortality and reduced quality of life. ${ }^{29}$ Mechanisms leading to anemia in COPD patients are multifactorial and include chronic inflammatory state, renal impairment, androgen deficiency, malnutrition and therapy side effects. ${ }^{29}$ Interestingly, reduced GFR was seen in patients from both groups in our study, so that it seems that renal impairment was not the leading causative factor for the development of anemia in this COPD patient collective. Another possible cause of anemia could be iron deficiency. Typical pattern for the iron-deficiency anemia is microcytosis (reduced $\mathrm{MCV}$ ), hypochromia (reduced $\mathrm{MCH}, \mathrm{MCHC}$ ) and elevated degree of anisocitosis (increased RDW). ${ }^{30}$ In our work, MCV did not differ between COPD and non-COPD groups. In contrast, $\mathrm{MCH}$ and $\mathrm{MCHC}$ were significantly lower and RDW was relevantly higher compared with the non-COPD patients. As up to $40 \%$ of iron-deficiency anemia cases are normocytic, the aforementioned laboratory characteristics of our COPD patient collective could indicate incipient irondeficiency anemia. ${ }^{30}$ Indeed, systemic inflammation-driven 
disturbed iron homeostasis is common among COPD patients. Iron deficiency may augment hypoxemia-induced pulmonary hypertension in COPD individuals, which is an independent predictor for mortality. ${ }^{31}$ To clarify definitively the question of the possible iron deficiency underlying the anemia detected in our COPD patient group, the determination of further parameters of iron metabolism such as ferritin and transferrin saturation index would be helpful, especially to distinguish between absolute and functional iron deficiency. ${ }^{30}$

\section{Limitations}

Our work has some limitations such as a relatively low number of study participants and a determination of $\mathrm{pO}_{2}$ by means of capillary blood gas analysis. Whereas the capillary blood is a good alternative to arterial blood for the measurement of $\mathrm{pCO}_{2}$, the assessment of $\mathrm{pO}_{2}$ in the capillary blood may not accurately reflect the analogical measurements conducted in the arterial blood. However, such a procedure may be appropriate unless high precision is required and when earlobe capillary instead of fingertip capillary is a puncture site and a post-sampling analysis time is short. ${ }^{32,33}$ All these conditions were fulfilled in our study.

Further limitation of our work is the lack of data providing quantification of symptoms by use of appropriate scales or assessment tests. Generally, spirometric screening of asymptomatic non-smokers is not recommended in order to avoid overtreatment associated with high costs and potential side effects. However, many patients tend to underestimate their symptoms, which leads to the failure of the early treatment and in consequence, to the further development of the disease with its complications. ${ }^{34}$ Therefore, assessment of the symptoms seems to be helpful, but not decisive with respect to the initiation of the therapy.

\section{Conclusion}

Taken together, our present study showed a high prevalence of COPD among patients with atherosclerotic artery disease. COPD individuals were characterized by the predominance of diabetes mellitus, neutrophilic inflammation and anemia.

\section{Disclosure}

The authors report no conflicts of interest in this work.

\section{References}

1. Wong ND. Epidemiological studies of CHD and the evolution of preventive cardiology. Nat Rev Cardiol. 2014;11(5):276-289.
2. Rabe KF, Hurd S, Anzueto A, et al. Global Initiative for Chronic Obstructive Lung Disease. Global strategy for the diagnosis, management, and prevention of chronic obstructive pulmonary disease: GOLD executive summary. Am J Respir Crit Care Med. 2007;176(6):532-555.

3. Ghoorah K, De Soyza A, Kunadian V. Increased cardiovascular risk in patients with chronic obstructive pulmonary disease and the potential mechanisms linking the two conditions: a review. Cardiol Rev. 2013; 21(4):196-202.

4. Sabater-Lleal M, Mälarstig A, Folkersen L, et al. Common genetic determinants of lung function, subclinical atherosclerosis and risk of coronary artery disease. PLoS One. 2014;9(8):e104082.

5. Chandra D, Gupta A, Strollo PJ Jr, et al. Airflow limitation and endothelial dysfunction. Unrelated and independent predictors of atherosclerosis. Am J Respir Crit Care Med. 2016;194(1):38-47.

6. Topsakal R, Kalay N, Ozdogru I, et al. Effects of chronic obstructive pulmonary disease on coronary atherosclerosis. Heart Vessels. 2009; 24(3):164-168.

7. Pauwels RA, Buist AS, Calverley PM, Jenkins CR, Hurd SS; GOLD Scientific Committee. Global strategy for the diagnosis, management, and prevention of chronic obstructive pulmonary disease. NHLBI/WHO global initiative for chronic obstructive lung disease (GOLD) workshop summary. Am J Respir Crit Care Med. 2001;163(5):1256-1276.

8. Vogelmeier CF, Criner GJ, Martínez FJ, et al. Global Strategy for the diagnosis, management, and prevention of chronic obstructive lung disease 2017 report: GOLD executive summary. Am J Respir Crit Care Med. 2017;195(5):557-582.

9. Global initiative for chronic obstructive lung disease, Inc.; Global Strategy for the Diagnosis, Management and Prevention of chronic obstructive pulmonary disease. 2017 Report. [updated 2017]. Available from: http://goldcopd.org. Accessed July 9, 2017.

10. Schaefer CA, Adam L, Weisser-Thomas J, et al. High prevalence of peripheral arterial disease in patients with obstructive sleep apnoea. Clin Res Cardiol. 2015;104(9):719-726.

11. Fontaine R, Kim M, Kieny R. Surgical treatment of peripheral circulation disorders [in German]. Helv Chir Acta. 1954;21(5-6):499-533.

12. Quanjer PH, Stanojevic S, Cole TJ, et al. Multi-ethnic reference values for spirometry for the 3-95-yr age range: the global lung function 2012 equations. Eur Respir J. 2012;40(6):1324-1343.

13. Blanc B, Finch CA, Hallberg L, Lawkowicz W, Layrisse M, Mollin DL. Nutritional anaemias: report of a WHO Scientific Group. WHO Tech Rep Ser. 1968;405:1-40.

14. Levey AS, Stevens LA, Schmid CH, et al. A new equation to estimate glomerular filtration rate. Ann Intern Med. 2009;150(9):604-612.

15. Levey AS, Inker LA, Coresh J. GFR estimation: from physiology to public health. Am J Kidney Dis. 2014;63(5):820-834.

16. Geldmacher H, Biller H, Herbst A, et al. The prevalence of chronic obstructive pulmonary disease (COPD) in Germany. Results of the BOLD study. Dtsch Med Wochenschr. 2008;133(50):2609-2614.

17. Fukahori S, Matsuse H, Takamura N, et al. Prevalence of chronic obstructive pulmonary diseases in general clinics in terms of FEV1/ FVC. Int J Clin Pract. 2009;63(2):269-274.

18. Kamimura T, Koga T, Oshita Y, et al. Prevalence of previously undiagnosed airflow limitation in patients who underwent preoperative pulmonary function test. Kurume Med J. 2006;53(3-4):53-57.

19. Hadi HA, Zubaid M, Al Mahmeed W, et al. Prevalence and prognosis of chronic obstructive pulmonary disease among 8167 Middle Eastern patients with acute coronary syndrome. Clin Cardiol. 2010;33(4): 228-235.

20. Matsumoto K, Takahashi Y, Gon Y, et al. Identifying unrecognized airflow obstruction in cases with lifestyle-related diseases using a data mining system with electronic medical records. Rinsho Byori. 2011; 59(2):128-133.

21. Barisione G, Pellegrino R. Body plethysmography is helpful for COPD diagnosis, determination of severity, phenotyping, and response to therapy. COPD. 2015;12(6):591-594. 
22. Rogliani $\mathrm{P}$, Lucà G, Lauro D. Chronic obstructive pulmonary disease and diabetes. COPD Res Pract. 2015;1:3.

23. Botelho FM, Bauer CM, Finch D, et al. IL-1 $\alpha /$ IL-1R1 expression in chronic obstructive pulmonary disease and mechanistic relevance to smoke-induced neutrophilia in mice. PLoS One. 2011;6(12):e28,457.

24. Moermans C, Heinen V, Nguyen M, et al. Local and systemic cellular inflammation and cytokine release in chronic obstructive pulmonary disease. Cytokine. 2011;56(2):298-304.

25. Briggs DD Jr. Chronic obstructive pulmonary disease overview: prevalence, pathogenesis, and treatment. J Manag Care Pharm. 2004; 10(4 Suppl):S3-S10.

26. Pera T, Atmaj C, van der Vegt M, Halayko AJ, Zaagsma J, Meurs H. Role for TAK1 in cigarette smoke-induced proinflammatory signaling and IL-8 release by human airway smooth muscle cells. Am J Physiol Lung Cell Mol Physiol. 2012;303(3):L272-L278.

27. Han MK, McLaughlin VV, Criner GJ, Martinez FJ. Pulmonary diseases and the heart. Circulation. 2007;116(25):2992-3005.

28. Gan WQ, Man SF, Senthilselvan A, Sin DD. Association between chronic obstructive pulmonary disease and systemic inflammation: a systematic review and a meta-analysis. Thorax. 2004;59(7):574-580.
29. Robalo Nunes A, Tátá M. The impact of anaemia and iron deficiency in chronic obstructive pulmonary disease: A clinical overview. Rev Port Pneumol (2006). 2017;23(3):146-155.

30. Bermejo F, Garcia-Lopez S. A guide to diagnosis of iron deficiency and iron deficiency anemia in digestive diseases. World J Gastroenterol. 2009;15(37):4638-4643.

31. Nickol AH, Frise MC, Cheng HY, et al. A cross-sectional study of the prevalence and associations of iron deficiency in a cohort of patients with chronic obstructive pulmonary disease. BMJ Open. 2015;5(7): e007911.

32. Zavorsky GS, Cao J, Mayo NE, Gabbay R, Murias JM. Arterial versus capillary blood gases: a meta-analysis. Respir Physiol Neurobiol. 2007; 155(5):268-279.

33. Smajić J, Kadić D, Hasić S, Serdarević N. Effects of post-sampling analysis time, type of blood samples and collection tubes on values of blood gas testing. Med Glas (Zenica). 2015;12(2):108-112.

34. Ferreira AJ, Reis A, Marçal N, Pinto P, Bárbara C; COPD. A stepwise or a hit hard approach? Rev Port Pneumol (2006). 2016;22(4):214-221.
International Journal of COPD

\section{Publish your work in this journal}

The International Journal of COPD is an international, peer-reviewed journal of therapeutics and pharmacology focusing on concise rapid reporting of clinical studies and reviews in COPD. Special focus is given to the pathophysiological processes underlying the disease, intervention programs, patient focused education, and self management protocols.

\section{Dovepress}

This journal is indexed on PubMed Central, MedLine and CAS. The manuscript management system is completely online and includes a very quick and fair peer-review system, which is all easy to use. Visit http://www.dovepress.com/testimonials.php to read real quotes from published authors.

Submit your manuscript here: http://www.dovepress.com/international-journal-of-chronic-obstructive-pulmonary-disease-journal 